\title{
Straight-forward Synthesis of Sponge-sphere like Cobalt Tungstate: An Efficient Photocatalyst for Dye Degradation
}

\author{
Leeladevi. K, Vinoth Kumar. J, Thiruppathi. M, Nagarajan. E.R
}

\begin{abstract}
Herein, we attempted for the synthesis of novel sponge-sphere like cobalt tungstate nanoparticles $\left(\mathrm{CoWO}_{4} \mathrm{NPs}\right)$ via simple co-precipitation technique without using any surfactant/templates. The as-prepared $\mathrm{CoWO}_{4} \mathrm{NPs}$ were characterized by various analytical and spectroscopic techniques such as XRD, FT-IR, SEM, EDX, UV-Visible and elemental mapping analysis. The photocatalytic activity of as-prepared nanoparticles was investigated by the degradation of cationic dye methylene blue (MB) under visible light irradiation. It exhibited excellent photocatalytic degradation with a decolorization efficiency of $94 \%$ within 90 min. In addition, this work gives a novel application of $\mathrm{CoWO}_{4} \mathrm{NPs}$ in environmental remediation.
\end{abstract}

Keywords: $\mathrm{CoWO}_{4}$, Methylene blue, photodegradation.

\section{INTRODUCTION}

It is well known that ecological system contamination due to the hasty development of industries and the immense growth of human beings. Water is the essential source for all kind of living things but the water resource are highly affected by the wastewater discharge from textile, dyeing, paper, and pharmaceutical productions are directly passed to natural resources without any proper treatment cause major health issues to humans society and aquatic animals also [1]. Nowadays, there are lots of treatments used for the wastewater containing organic pollutants before discharging to the aquatic system. Methylene blue (MB) dye is mostly used in textile and dyeing industries. $M B$ is causing mutagenic and carcinogenic also it irritates the skin, eye, and respiratory acts. The various physical, chemical, and biological methods are present for the removal of organic pollutants from the dyeing industries, among the distinctive processes for removing the organic pollutants; the photocatalytic method is the most hopeful and eco-friendly. This method converts organic pollutants into nonlethal

Revised Manuscript Received on July 22, 2019

* Correspondence Author

Leeladevi. K, Department of Chemistry, Nanomaterials Laboratory, International Research Centre, Kalasalingam Academy of Research and Education, Krishnankoil-626126, Tamil Nadu India. Email: leela232323@gmail.com

Vinoth Kumar. J, Department of Chemistry, Nanomaterials Laboratory, International Research Centre, Kalasalingam Academy of Research and Education, Krishnankoil-626126, Tamil Nadu India. Email: vinothchem7@gmail.com

Thiruppathi. M, Department of Chemistry, Nanomaterials Laboratory, International Research Centre, Kalasalingam Academy of Research and Education, Krishnankoil-626126, Tamil Nadu India. Email: thiruppathi23@gmail.com

Nagarajan. E.R*, Department of Chemistry, Nanomaterials Laboratory, International Research Centre, Kalasalingam Academy of Research and Education, Krishnankoil-626126, Tamil Nadu India. Email: nagarajanklu@gmail.com compounds in an effortless manner [2-3]. The construction of the heterogeneous photocatalytic process with semiconductors is the most promising way for the complete degradation of organic pollutants. We planned to develop Cobalt tungstate $\left(\mathrm{CoWO}_{4}\right)$ nanoparticles as a photocatalyst. $\mathrm{CoWO}_{4}$ is a representative of p-type semiconductor and it exhibits lots of utilization like pigment additives, photovoltaic electrochemical cell and microwave dielectric ceramics and it shows excellent magnetic and electrical properties [4-5]. Because of its versatile application property, constructions of $\mathrm{CoWO}_{4}$ nanomaterials have gained more attention on the current scenario. Various methods are available for the synthesis of $\mathrm{CoWO}_{4}$ nanoparticles like spray pyrolysis, low-temperature molten salt route, co-precipitation, hydrothermal and solvothermal approaches [6-7]. We prepared a sponge-sphere like $\mathrm{CoWO}_{4}$ nanoparticles by a simple reaction between $\mathrm{CoCl}_{2}$ and $\mathrm{Na}_{2} \mathrm{WO}_{4}$, there is no use of any other hostile solvents. This way of preparation predominately gives a high percentage of yield affordably. Apart from its simplicity, this method yields a final product as much as perfect stoichiometry without high-temperature treatment. Besides, we studied the application of as prepared $\mathrm{CoWO}_{4}$ nanoparticles by the degradation of $\mathrm{MB}$ dye under the irradiation of visible light.

\section{EXPERIMENTAL SECTION}

\section{A. Materials}

Cobalt chloride hexahydrate $\left[\mathrm{CoCl}_{2} \cdot 6 \mathrm{H}_{2} \mathrm{O}\right]$, sodium tungstate dihydrate $\left[\mathrm{Na}_{2} \mathrm{WO}_{4} \cdot 2 \mathrm{H}_{2} \mathrm{O}\right]$ and urea $\left[\mathrm{NH}_{2} \mathrm{CONH}_{2}\right]$ have been used for the preparation of cobalt tungstate. All the chemicals were purchased from Merck chemical industries and which are used without any further purification.

\section{B. Synthesis of $\mathrm{CoWO}_{4}$}

The $\mathrm{CoWO}_{4}$ nanoparticles were synthesized by a simple co-precipitation method. In the typical synthesized procedure, an equimolar ratio of $\mathrm{Na}_{2} \mathrm{WO}_{4} \cdot 2 \mathrm{H}_{2} \mathrm{O}$ and $\mathrm{CoCl}_{2} \cdot 6 \mathrm{H}_{2} \mathrm{O}$ was dissolved in $60 \mathrm{ml}$ of aqueous solution (A). After $10 \mathrm{~min}$ of magnetic stirring $0.2 \mathrm{~g}$ of urea was dissolved in $10 \mathrm{ml}$ of aqueous solution (B), solution B was slowly mixed to solution $\mathrm{A}$ and the stirring was continued for further $30 \mathrm{~min}$. The obtained particles were repeatedly washed with water and ethanol and dried out at $85{ }^{\circ} \mathrm{C}$ of $10 \mathrm{~h}$. Finally, the product being grinded simply.

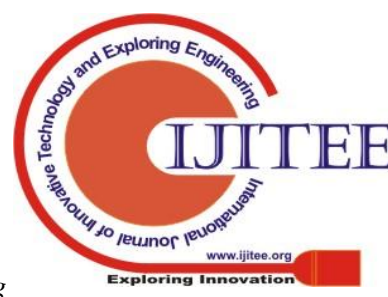




\section{Characterization of $\mathrm{CoWO}_{4}$ nanoparticles}

FT-IR spectrum was obtained from the IR Tracer-100 FT-IR spectrophotometer. The phase purity and crystalline nature of as-prepared nanoparticles were characterized by an X-ray diffractometer (Bruker) (D8 Advance ECO XRCD Systems with SSD160 1 D Detector). The particle size and structural morphology of $\mathrm{CoWO}_{4}$ were obtained from scanning electron microscopy (EVO-18, CARL ZEISS) and UV- visible spectrophotometer (Model UV-1800) Shimadzu, was used to detect the concentration depletion takes place in the organic pollutants.

\section{Photocatalytic activity}

The photocatalytic activity of as-synthesized $\mathrm{CoWO}_{4}$ nanoparticles was examined by the degradation of MB dye in water solution by the irradiation of visible light $(\lambda>400 \mathrm{~nm})$. Tungsten lamp $\left(150 \mathrm{~mW} / \mathrm{cm}^{-2}\right)$ was used as a source of light energy. The reactions were carried out in a photocatalytic reactor with a circulating water system at $25^{\circ} \mathrm{C} .100 \mathrm{ml}$ of MB dye solution and definite amount of as-prepared photocatalyst were dispersed in $250 \mathrm{ml}$ beaker and stirred up to $30 \mathrm{~min}$ for adsorption-desorption equilibrium in dark. The blended solution was taken at the exact time of interval during the photocatalytic reaction. Followed by the centrifugation, the solutions were examined by UV-Vis spectrometer.

\section{RESULTS AND DISCUSSION}

\section{A. FT-IR spectroscopy}

Fourier transmission infrared (FT-IR) spectroscopy is a technique used to predict the functional group presented and surface composition. Fig. 1 displays the FT-IR spectrum of $\mathrm{CoWO}_{4}$ nanoparticles between the ranges of $400-4000 \mathrm{~cm}^{-1}$ frequency. The bands observed the region $400-900 \mathrm{~cm}^{-1}$ were assigned to the metal-oxygen bond stretching vibration. The bands presented around $800 \mathrm{~cm}^{-1}$ was corresponding to the Co-O stretching [8]. The absorption bands around $3300 \mathrm{~cm}^{-1}-3500 \mathrm{~cm}^{-1}$ and $1660 \mathrm{~cm}^{-1}$ have represented the stretching of the $\mathrm{O}-\mathrm{H}$ bond and bending vibration of water molecules.

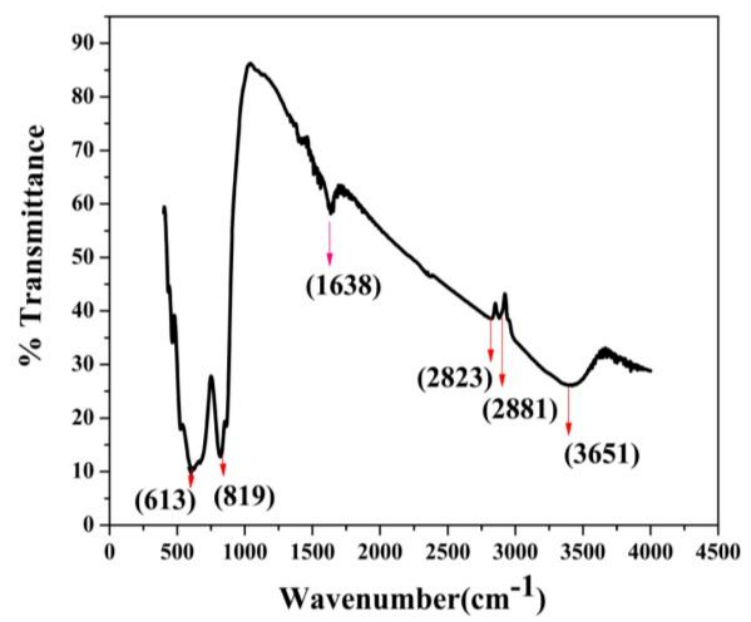

Fig. 1.FT-IR image of $\mathrm{CoWO}_{4}$ nanoparticles.

\section{B. X-ray diffraction analysis}

The crystal structures were characterized by X-ray diffraction (XRD) analysis. The XRD pattern of as-prepared
$\mathrm{CoWO}_{4}$ is well-matched with JCPDS (File No 72-0479) data of the monoclinic system. All the peaks were narrow and sharp, denoting the high crystallinity of nanoparticles. The observed major diffraction peaks in the $2 \theta$ range at $18.9,23.8$, $24.6,30.6,36.2,36.4,41.3,53.9,54.0,61.7$ and $65.0^{\circ}$ assigned respectively to (100), (011), (110), (111), (002), (021), (121), (202), (221), (113) and (132) miller indices plane of monoclinic $\mathrm{CoWO}_{4}$ with the phase group of $\mathrm{P} 2 / \mathrm{C}$ and also which shows cell parameters value $\mathrm{a}=4.669, \mathrm{~b}=5.687, \mathrm{c}$ $=4.951$. No characteristic peaks from impurities are detected, which indicates that the products are highly phase-pure. Fig. 2 shows the XRD pattern of $\mathrm{CoWO}_{4}$ nanoparticles.

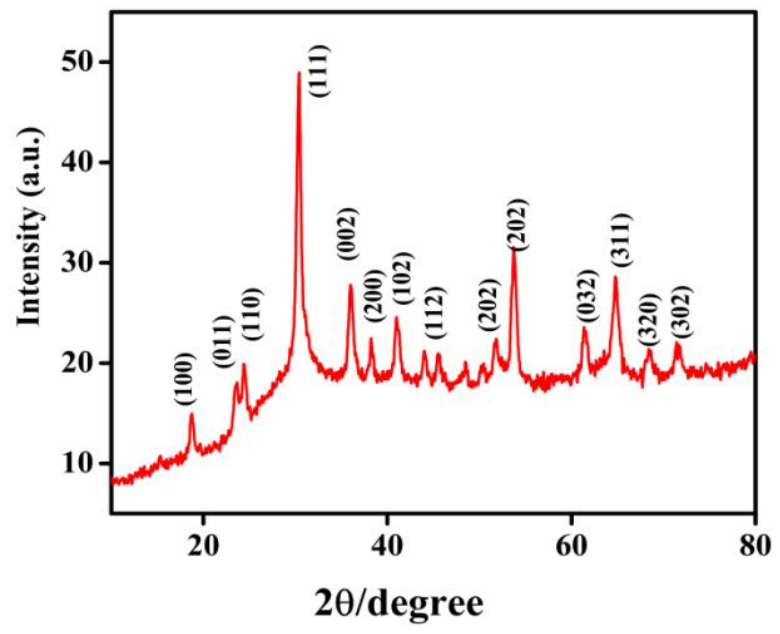

Fig. 2. XRD pattern of $\mathrm{CoWO}_{4}$ nanoparticles.

\section{Surface morphology}

The surface morphology of as-synthesized $\mathrm{CoWO}_{4}$ was predicted by scanning electron microscope (SEM) analysis. The image of the SEM shows that the sponge sphere-like structure of $\mathrm{CoWO}_{4}$ (Fig. 3). The result shows that as prepared sponge sphere-like $\mathrm{CoWO}_{4}$ are randomly arranged to one another. From the SEM image, we also concluded that nearly $100 \%$ of $\mathrm{CoWO}_{4}$ nanospheres were comfortably obtained by a co-precipitation method. Further, the EDX spectrum (Fig. 4) confirmed the presence of $\mathrm{Co}, \mathrm{W}$ and $\mathrm{O}$ elements only presented in the $\mathrm{CoWO}_{4}$ composite and Fig. 5 revealed the elemental color mapping analysis of $\mathrm{CoWO}_{4}$. It gives the complete dispensation of $\mathrm{O}, \mathrm{W}$ and Co elements on the $\mathrm{CoWO}_{4}$ composite. This also predicted the high purity of as prepared sponge-sphere like $\mathrm{CoWO}_{4}$.

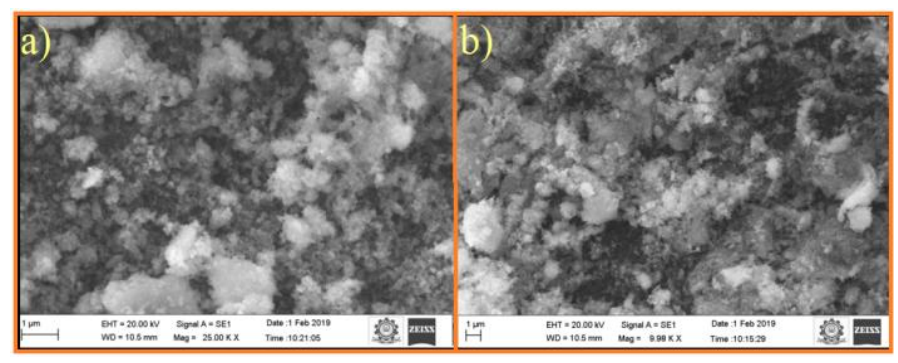

Fig. 3. SEM image of sponge-sphere like CoWO4. 


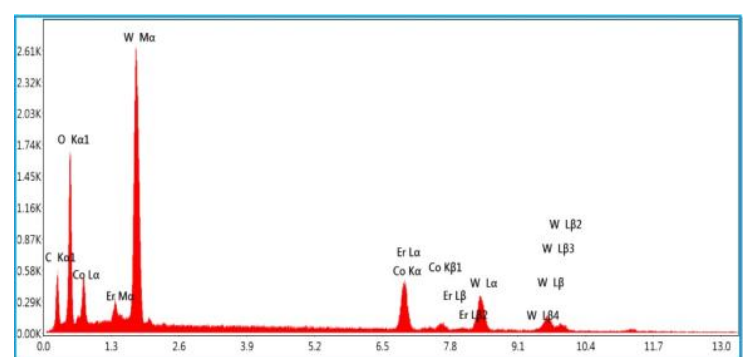

Fig. 4. EDX Spectrum of as prepared $\mathrm{CoWO}_{4}$ nanoparticles.
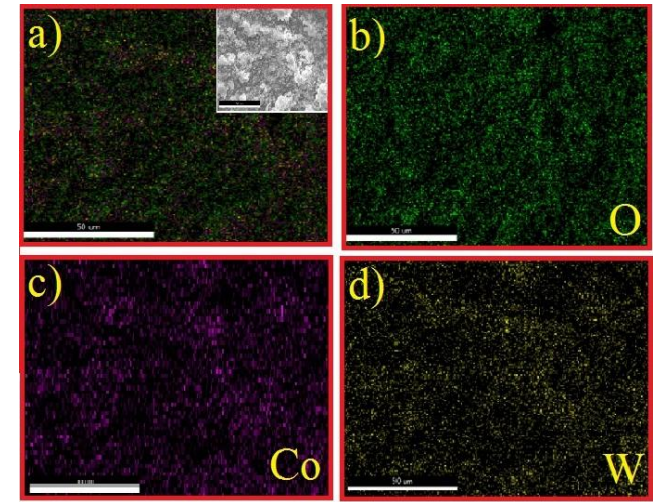

Fig. 5. Elemental color mapping image of $\mathrm{CoWO}_{4}$ nanoparticles. (a) $\mathrm{CoWO}_{4}$, (b) $\mathrm{O}$, (c) $\mathrm{Co}$, (d) W.

\section{Photocatalytic analysis}

The photocatalytic activity of as-prepared $\mathrm{CoWO}_{4}$ nanoparticles was investigated by the degradation of MB dye. Fig. 6 showed that the absorption peak values gradually decrease with an increasing period without the formation of new peaks. After 90 min of irradiation, the absorption peak value decreased to almost zero and it showed that complete degradation of $\mathrm{MB}$ was achieved by as prepared $\mathrm{CoWO}_{4}$ nanoparticles. As a result, the $\mathrm{CoWO}_{4}$ nanoparticles showed excellent photocatalytic activity with $94 \%$ MB under the irradiation visible light within $90 \mathrm{~min}$.

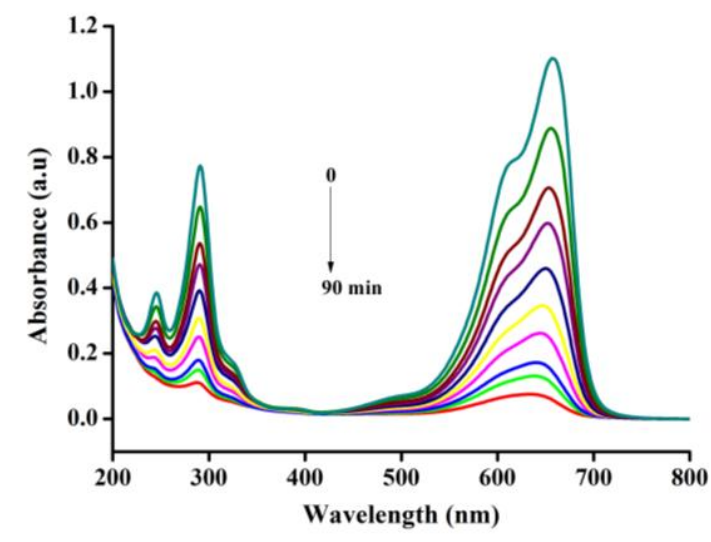

Fig. 6. Absorbance spectra of methylene blue degradation using $\mathrm{CoWO}_{4}$ nanoparticles.

\section{E. Mechanism of photocatalytic activity}

Under the irradiation of visible light $\mathrm{CoWO}_{4}$ nanoparticles generated electrons and holes. As generated holes react with the contaminated water to convert hydrogen ion into hydroxyl radicals and the electrons react with the oxygen to produced superoxide radicals [9-10]. Thus formed hydroxide and superoxide radicals achieve the degradation of MB. Fig. 7 represented the mechanism of the degradation of $\mathrm{MB}$ using $\mathrm{CoWO}_{4}$ nanoparticles.

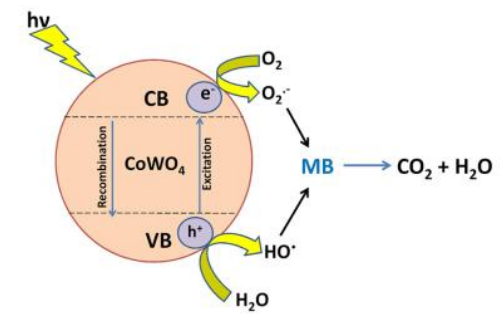

Fig. 7. Schematic representation of photodegradation of $\mathrm{MB}$ by using $\mathrm{CoWO}_{4}$ nanoparticles.

\section{F. Reusability}

The reusability of $\mathrm{CoWO}_{4}$ nanoparticles are analyzed by up to 4 cycles. It shows promising results for stability and reusability. Fig. 8 shows the reusability results of $\mathrm{CoWO}_{4}$.

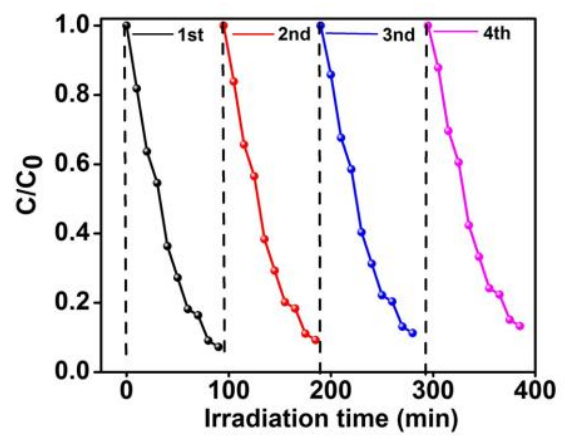

Fig. 8. Reusability study of $\mathrm{CoWO}_{4}$.

\section{CONCLUSION}

In summary, by using simple co-precipitate method $\mathrm{CoWO}_{4}$ nanoparticles were fabricated without any surfactant and characterized by XRD, FT-IR, SEM, EDX and UV-Visible techniques. The $\mathrm{CoWO}_{4}$ nanoparticles exhibit a sponge-sphere like nanostructure and it also shows excellent photocatalytic degradation of $\mathrm{MB}$ dye with decoloration efficiency of $94 \%$ under visible light irradiation within $90 \mathrm{~min}$ and repeated analysis showed that the $\mathrm{CoWO}_{4}$ nanocatalyst has high stability and reusability also. This study gives a hopeful way to develop the photocatalytic application of $\mathrm{CoWO}_{4}$.

\section{ACKNOWLEDGMENT}

The author, K. Leeladevi acknowledges Kalasalingam Academy of Research and Education for providing research fellowship and necessary facilities.

\section{REFERENCES}

1. M.S. Gohari, A.H. Yangjeh, " $\mathrm{Fe}_{3} \mathrm{O}_{4} / \mathrm{ZnO} / \mathrm{CoWO}_{4}$ nanocomposi tes: Novel magnetically separable visible-light -driven photocatalysts with enhanced activity in degradation of different dye pollutants," Ceram. Int., 43, 2017, 3063-3071.

2. X. Yan, Z. Wu, C. Huang, K. Liu, W. Shi, "Hydrothermal synthesis of 
$\mathrm{Cds} / \mathrm{CoWO}_{4}$ heterojunctions with enhanced visible light properties towards organic pollutants degradation," Ceram. Int., 43, 2017, 5388-5395.

3. M. Arunpandian, K. Selvakumar, A. Raja, P. Rajasekaran, M. Thiruppathi, E.R. Nagarajan, S. Arunachalam, "Fabrication of novel Nd2O3/ZnO-GO nanocomposite: An efficient photocatalyst for the degradation of organic pollutants," Colloids Surf. A, 567, 2019, 213-227.

4. P. Taneja, S. Sharma, A. Umar, S.K. Mehta, A.O. Ibhadon, S.K. Kansal, "Visible-light driven photocatalytic degradation of brilliant green dye based on cobalt tungstate $\left(\mathrm{CoWO}_{4}\right)$ nanoparticles," Mater. Chem. Phys., $211,2018,335-342$.

5. K. Jothivenkatachalam, S. Prabhu, A. Nithya, S. Chandramohan, K. Jeganathan, "Solar, visible and UV light photocatalytic activity of $\mathrm{CoWO}_{4}$ for the decolorization of methyl orange," Desalination Water Treat., 54, 2014, 3134-3145.

6. F. Ahmadi, M.R. Nasrabadi, A. Fosooni, M. Daneshmand, "Synthesis and application of $\mathrm{CoWO}_{4}$ nanoparticles for degradation of methyl orange," $J$. Mater. Sci., 27, 2016, 9514-9519.

7. Z. Liu, J. Xu, Y. Li, H. Yu, "High performance photocatalytic based on Ce doped $\mathrm{CoWO}_{4}$ controllable synthesis and enhanced photocatalytic activity," Catal. Lett., 148, 2018, 3205-3213.

8. L. Zhen, W. S. Wang, C.Y. Xu, W.Z. Shao, L.C. Qin, "A facile hydro thermal route to large-scale synthesis of $\mathrm{CoWO}_{4}$ nanorods," Mater. Lett., 62, 2008, 1740-1742.

9. M.I. Ahmed, A. Adam, A. Khan, A.U. Rehman, M. Qamaruddin, M.N. Siddiqui, "Improved photoelectrochemical water oxidation under visible light with mesoporous $\mathrm{CoWO}_{4}, "$ Mater. Lett., 183, 2016, 281-284.

10. M. Thiruppathi, K. Selvakumar, M. Arunpandian, K. Thirumalai, C. Ramalingan, M. Swaminathan, E.R. Nagarajan, "An affordable photocatalyst for pharmaceuticals and superior electrocatalyst for methanol oxidation - A dual role by $\mathrm{CuWO}_{4}$ anchored bentonite clay," Colloids Surf. A Physicochem. Eng. Asp., 563, 2019, 148-159.

\section{AUTHORS PROFILE}

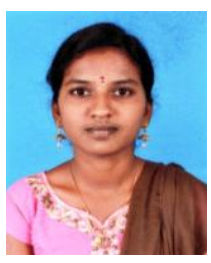

K. Leeladevi is a research scholar at Nanomaterial Laboratory, Department of Chemistry, International Research Centre, Kalasalingam Academy of Research and Education, Krishnankoil, Tamil Nadu, India. Her research interest is in synthesis of nanomaterials for waste water purification and Photocatalysis.

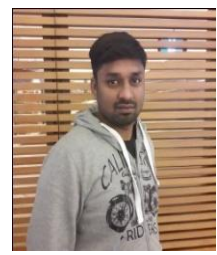

J. Vinoth Kumar is a Post-doctoral fellow at Kalasalingam Academy of Research and Education, Krishnankoil, India. He got his Ph.D Degree from Madurai Kamaraj University, Madurai, India. He is interested in synthesis of nanomaterials for photocatalysis and electrocatalysis applications.

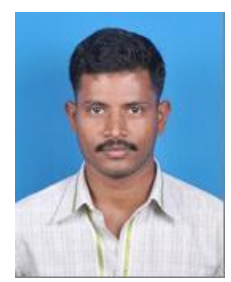

M. Thiruppathi is a research scholar at Nanomaterial Laboratory, Department of Chemistry, International Research Centre, Kalasalingam Academy of Research and Education, Krishnankoil, Tamil Nadu, India. He is working under the area of materials Characterization, waste water purification and Photocatalysis.

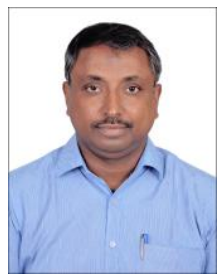

E.R. Nagarajan works as Associate Professor, Department of Chemistry, Kalasalingam Academy of Research and Education, Krishnankoil, Tamil Nadu, India. He received his Ph.D degree at Anna University, Chennai, India. With a research in the applications of polymeric materials, co-ordination compounds, photocatalysis and electrochemical applications. 